\title{
A ARQUITETURA DE ANTON BENJAMIN FLODERER: UM DISCÍPULO DE OTTO WAGNER NO BRASIL
}

\author{
Liszt Vianna Neto ${ }^{1}$
}

DOI: 10.5752/P.2316-1752.2020v27n40p57

\begin{abstract}
Resumo
Este artigo trata da trajetória de Anton Benjamin Floderer, arquiteto austríaco, ex-aluno de Otto Wagner e ativo no campo arquitetônico berlinense que imigrou para o Rio de Janeiro em 1923, quando associou-se a arquitetos imigrados como R. Prentice e A. Buddeus. No Brasil, Floderer teve uma vasta produção, versada sobre linguagens arquitetônicas diversas. Com a trajetória de Floderer, visamos demonstrar que o campo arquitetônico brasileiro foi mais diverso em suas linguagens arquitetônicas e em seus diálogos com o proto-modernismo europeu do que a historiografia apontou até hoje.
\end{abstract}

Palavras-chave: Anton Floderer. Otto Wagner. Modernismo brasileiro. Imigrados de língua alemã.

\footnotetext{
1. Liszt Vianna Neto é historiador (UFMG/2008), Doutor em Humanidades pela Universidade de Leiden (Países Baixos/2020), Mestre em Arquitetura e Urbanismo (UFMG/2014), Mestre em História (UFMG/2011), e tem atuado como Professor pela UFMG e PUC Minas. Contato: lisztvianna@gmail.com
} 


\section{ANTON BENJAMIN FLODERER'S ARCHITEC- TURE AND THE INFLUENCE OF THE WAGNER- SCHULE IN BRAZIL}

\begin{abstract}
This paper concerns the trajectory of Anton Benjamin Floderer, Austrian architect, former Otto Wagner's student, active in the Berlin architectural field who immigrated to Rio de Janeiro in 1923, when he joined immigrants such as R. Prentice and $A$. Buddeus. In Brazil, Floderer had a vast production, versed in different architectural languages. With Floderer's trajectory, we aim to demonstrate that the Brazilian architectural field was more diverse in its architectural languages and dialogues with European proto-modernism than historiography has pointed out so far.
\end{abstract}

Keywords: Anton Floderer. Otto Wagner. Brazilian modernism. German-speaking immigrants

\section{LA ARQUITECTURA DE ANTON BENJAMIN FLODERER Y LA INFLUENCIA DE LA WAGNER- SCHULE EN BRASIL}

\begin{abstract}
Resumen
Este artículo trata de la trayectoria de Anton Benjamin Floderer, arquitecto austriaco, ex alumno de Otto Wagner, actuante en el campo de la arquitectura de Berlín que inmigró a Río de Janeiro en 1923, cuando se asoció a arquitectos inmigrados como R. Prentice y A. Buddeus. En Brasil, Floderer tuvo una vasta producción, versada en diferentes lenguajes arquitectónicos. Con la trayectoria de Floderer pretendemos demostrar que el campo arquitectónico brasileño era más diverso en sus lenguajes arquitectónicos y diálogos con el protomodernismo europeo de lo que la historiografía ha señalado hasta hoy.
\end{abstract}

Palabras-claves: Anton Floderer. Otto Wagner. Modernismo brasileño. Inmigrantes de idioma alemán.. 
A importância da imigração de língua alemã para as Américas no período entreguerras é notável em diversos campos da cultura: basta lembrarmos de alguns exemplos, como Walter Gropius, Erwin Panofsky, Thomas Mann, Bertold Brecht, George Grosz, entre tantos outros. Tratamos aqui da vibrante vida artística e cultural da comunidade de língua alemã imigrada para o Brasil e de como sua atuação foi fundamental para o desenvolvimento do modernismo no país. Os primeiros arquitetos modernos no Brasil, vários deles imigrados europeus como G. Warchavchik, A. Altberg, A. Buddeus, etc., lançaram as bases para formação de um campo artístico modernista: publicaram os primeiros manifestos, as primeiras revistas modernistas, projetaram e executaram as primeiras obras, formaram a primeira geração de arquitetos modernos, impeliram a formação de uma crítica especializada, moldando o gosto do público e criando meios de circulação, consumo e consagração do modernismo nacional.

Sabemos, no entanto, que no mesmo período, especialmente durante a Era Vargas (1930-1945), o Estado brasileiro passou a ter um papel mais direto no mecenato artístico. Se o chamado Art Decó foi a principal dicção arquitetônica representada pela "Obra Getuliana", o Ministério da Educação e Saúde Pública de Gustavo Capanema seria o grande responsável por consolidar uma matriz modernista como discurso da nação em plena modernização, através da "Escola Carioca", capitaneada por Lúcio 
Costa, junto a seus ex-alunos e associados (REIS, 2014). Tratamos, entretanto, de um "outro modernismo carioca", um modernismo imigrado, de matriz alemã, representado aqui por Anton Benjamin Floderer (1884-1972), arquiteto nascido em Brünn, ou Brno cidade natal de Adolf Loos, antigo Império Austro-Húngaro, atual República Tcheca. Antes de emigrar para as Américas, Floderer esteve envolvido com movimentos e matrizes arquitetônicas proto-modernas ainda não propriamente rastreadas no Brasil: foi discípulo do eminente arquiteto vienense Otto Wagner, associou-se a diversos arquitetos do neo-historicismo berlinense e, ao emigrar para o Brasil, desenvolveu uma dicção arquitetônica muito própria e diversa, que oscilava entre os historicismos, o Expressionismo Alemão e o Art Decó Marajoara.

Abrangeremos aqui dois períodos da trajetória de Floderer. O primeiro, período préimigração (1905-1923), compreende os anos formativos do arquiteto na chamada Wagnerschule, assim como sua atuação no campo arquitetônico berlinense, no qual Floderer se associou aos escritórios de Bruno Schmitz, Robert Leibnitz, Oskar Kauffman, entre outros, além de atuar como autônomo e como professor. Já o segundo, período pósimigração (1923-1939), corresponde aos anos que Floderer percorreu o Brasil do Rio Grande do Sul à Bahia, associado aos arquitetos imigrados Alexander Siegfried Buddeus e Robert Prentice, obtendo considerável sucesso profissional 
ao valer do mecenato dos governos Vargas, durante seus projetos de modernização. O período que compreende a Segunda Guerra Mundial foi marcado pelo retorno de Floderer à Áustria e por sua reemigracão ao Brasil no final da década de 1950, eventos que escapam ao nosso recorte temporal por ocorrerem em um período fundamentalmente diverso das primeiras manifestações do modernismo arquitetônico no Brasil.

No contexto de formação do modernismo nos países de língua alemã no início do século XX, as capitais Viena e Berlim se destacam claramente como centralidades. Viena se destaca pelas matrizes proto-modernas de Otto Wagner e da Wiener Secession, atuantes desde 1897 e, posteriormente, pela radicalidade da teoria crítica de Adolf Loos. Berlim se destaca por condensar as matrizes modernistas do país, albergando exposições e projetos do Deutscher Werkbund em 1924 e, em seguida, como sede do Bauhaus, em seus últimos suspiros. Anton Floderer teve a oportunidade de passar seus anos formativos em ambos os contextos modernistas, primeiro como aluno da Wagnerschule, em Viena, depois como jovem arquiteto em escritórios berlinenses.

Desde muito cedo, Floderer teve sua formação voltada para a construção e para as artes e ofícios: frequentou a Staatsgewerbeschule (1898-1903) e a Technische Hochschule (1904-1905), ambas em Viena. Já na idade adulta, 
teve sua formação superior na chamada Wagnerschule, nome que se refere à Akademie der Bildenden Künste, Spezialeschule für Architektur, Wien (Escola Especial de Arquitetura da Academia de Artes Visuais de Viena) dirigida por Otto Wagner. Para ingressar na Wagnerschule, jovens talentos como Floderer eram entrevistados e selecionados, com seus projetos em mão, por Otto Wagner pessoalmente. Muitos dos candidatos inscritos para a estrita seleção já eram arquitetos ativos e reconhecidos, algo meritório para o jovem Floderer. Ainda, dentre as mais de seis dezenas de candidatos anuais inscritos, apenas oito em média eram aprovados. Em duas décadas de existência da escola, apenas cerca de 190 arquitetos foram admitidos e somente um terço desses se formaram pela escola (GRUEFF, 1989).

Dos três anos de formação previstos pelo currículo da instituição, os alunos contavam com a orientação pessoal de Otto Wagner a partir do segundo ano. No último ano de formação, Wagner demandava dos alunos uma libertação total das restrições impostas nos projetos executados nos semestres anteriores, propondo uma Phantasie que impelisse seus discípulos a demonstrar livremente todo seu potencial no projeto final. Além das Phantasien propostas, o exercício das perspectivas, vedute e projetos monumentais geraram uma intensa prática do desenho na escola, fazendo com que muitos alunos se dedicassem às artes gráficas e à pintura após formados. A proximida- 
de de Wagner de seus alunos é algo realmente excepcional no sistema acadêmico norte-europeu do período, e sugere uma proximidade valiosa entre o jovem Floderer e seu mestre Otto Wagner (BORSI; GODOLI, 1985).

Dentre os alunos da Wagnerschule, pode-se afirmar que predominavam quatro dicções arquitetônicas vigentes, sendo que apenas uma delas se alinharia mais claramente ao modernismo, à abstração, à síntese e ao funcionalismo, mesmo que avant la lettre. Oposta a essa, havia a tendência ao ornamental, ao decorativismo bidimensional, ao desenho e ao tratamento planar, muitas vezes afiliada ao Art Nouveau. Uma terceira dicção mantinha um certo classicismo contido, ainda historicista e monumental, mas abstrato e revisitado. Finalmente, coexistia entre essas vertentes o apreço pela arquitetura popular, tradicional e vernacular, próxima ao chamado Heimatstil.

Apesar das vertentes neo-historicistas estarem presentes na Wagnerschule, o discurso Wagneriano era radicalmente anti-historicista: "O ponto de partida para qualquer criação artística deve ser as necessidades, as possibilidades, os meios e as qualidades de nossa própria era" (VYBIRAL, 2005, p. 3-7). Tal discurso modernizador de Wagner visava, dentre outras coisas, defender a Escola do conservadorismo da crítica vienense e, concomitantemente, aproximar a escola da Wiener Secession e de outros arquitetos modernos, como Josef Maria Olbrich e 
Adolf Loos (POZZETTO, 1980). Contratado para a Akademie pela primeira geração de semperianos, Wagner renegou o neo-renascentismo vigente, usando as palavras do próprio Gottfried Semper: "artis sola domina necessita", interpretada livremente por ele como "forma segue a função". Contudo, para além do front conservador, Wagner não se blindou totalmente dos ataques modernistas mais radicais, que vituperavam sua dicção modernizadora por ser uma "arquitetura tatuada", um trabalho de superfícies, decorativista (GRAF, 1969).

A tabula rasa modernista de Wagner, no entanto, se manifestava no cotidiano da escola. O curso, por exemplo, não incluía em seu programa um tour a Roma, como as demais academias tradicionalmente faziam: "Ao se percorrer por toda criação estilística das décadas passadas, nenhuma salvação se pode esperar para o futuro" (GRUEFF, 1989, p.7-27). Não obstante, a Wagnerschule cumpria papel hegemônico nos prêmios e postos oferecidos pelo Império Austro-Húngaro aos jovens arquitetos. Ao longo dos anos, a escola recebeu 24 bolsas de viagem, restando apenas 9 bolsas para as demais instituições (GRUEFF, 1989). Tal proeminência deu à escola um escopo de uma verdadeira academia imperial: quase metade de seus alunos vieram de territórios fora da Áustria, como o próprio Floderer. Tendo a Hungria menor representatividade na Wagnerschule, por conta da autonomia de seu campo arquitetônico dentro do Império Austro-Húngaro, a Escola 
atendeu em larga medida ao crescente nacionalismo dos Balcãs, ao qual, como veremos, os projetos de Floderer para Sarajevo prestam testemunho. Wagner, entretanto, não escondia sua ambição de alcançar o escopo continental europeu: "Nós lideramos, nós avançamos triunfalmente, nós temos a hegemonia, entre nós estão as pessoas certas e a arte certa" (BORSI; GODOLI, 1985, p. 204).

Apesar da clara proeminência da Wagnerschule no campo arquitetônico vienense do período, poucos de seus alunos tiveram uma trajetória de sucesso na arquitetura, destacando-se apenas uns quantos: Josef Hoffmann, Joseph Maria Olbrich, Karl Ehn, Jože Plecnik e Max Fabiani, mas nenhum deles tão proeminentes quanto o próprio mestre. Apesar de se associar a arquitetos berlinenses bastante bem-sucedidos, Floderer tampouco pode ser apontado como expoente ou como um dos alunos laureados da Wagnerschule. Ainda que tenha participado da importante exposição da Wiener Messe em 1920, projetando a torre do relógio (Glockenturm - Figura 1), e que tenha se associado nesse período a clubes restritos, como o Österreischer Ingenieur und Architektenverein e o Künstlerhaus desde a década de 1920, Floderer não desponta claramente no campo arquitetônico vienense (WINKELHOFER, 2014). 


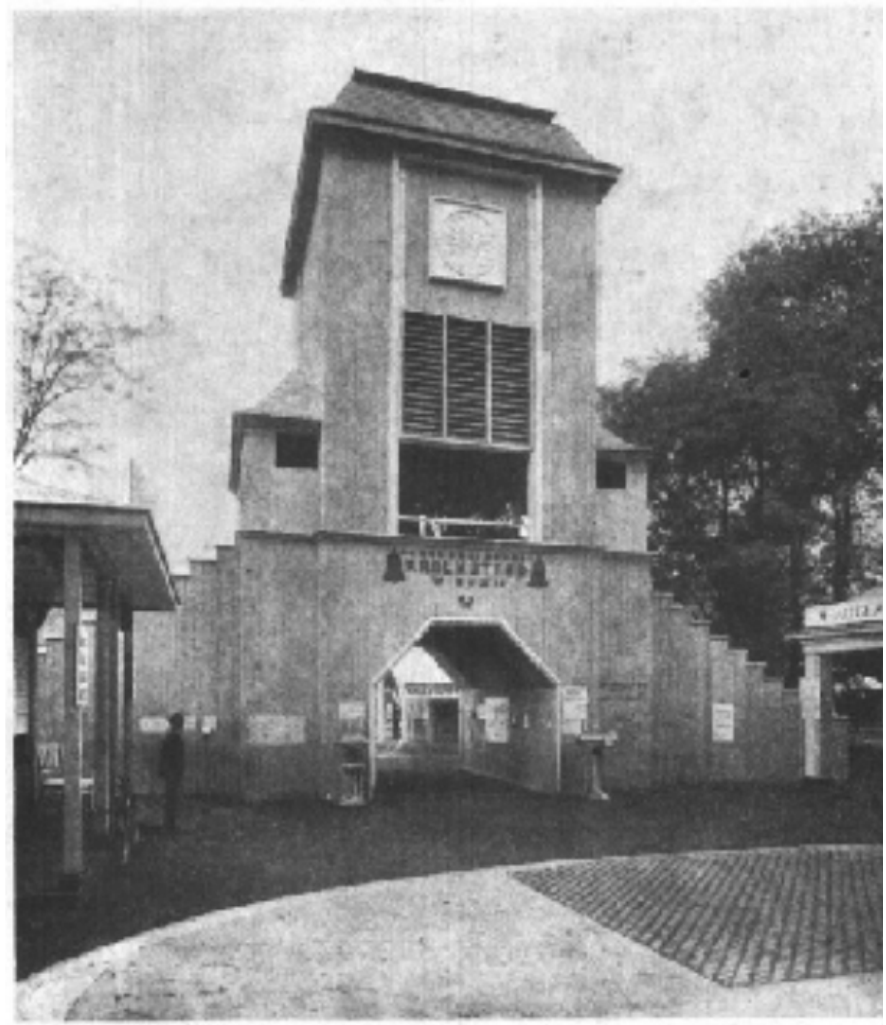

Figura 1 | "Glockenturm vor dem Westportal der Rotunde", Viena. Projeto de Anton Floderer.

Fonte: DER ARCHITEKT, Viena: 1921, p. 51. 
Otto Wagner acreditava pessoalmente que alguns de seus alunos foram vítimas de um trágico destino do contexto histórico, cujos turbilhões sociais de fato arrastaram os grandes representantes da cultura vienense moderna à guerra, à penúria, ao exílio e ao esquecimento. Não podemos deixar de pontuar que muitos de seus alunos trilharam caminhos neo-historicistas ou tradicionalistas como do Heimatstil - e, mais do que romperem com o historicismo, como o discurso de Wagner propunha, mantiveram o debate arquitetônico entorno dos formulários pretéritos (VYBÍRAL, 2007). Apesar das várias camadas de contradições entre o discurso de Wagner e a prática da Escola e de seus alunos, a Wagnerschule representou para a história da arquitetura um largo passo para além do historicismo, em direção ao modernismo (KURDIOVSKY; NIEHAUS; PICHLER, 2016). Quanto a Floderer, seus projetos na Wagnerschule aparentemente se alinhavam à matriz sintética e funcionalista da Escola. Um de seus projetos localizados (Figura 2), publicado no compêndio da Escola, apresenta tal tectônica ortogonal e sintética, ainda que seus frisos e contornos sejam exemplos do decorativismo bidimensional apontado pela crítica coetânea à Escola (WAGNER, 1905-1910). 


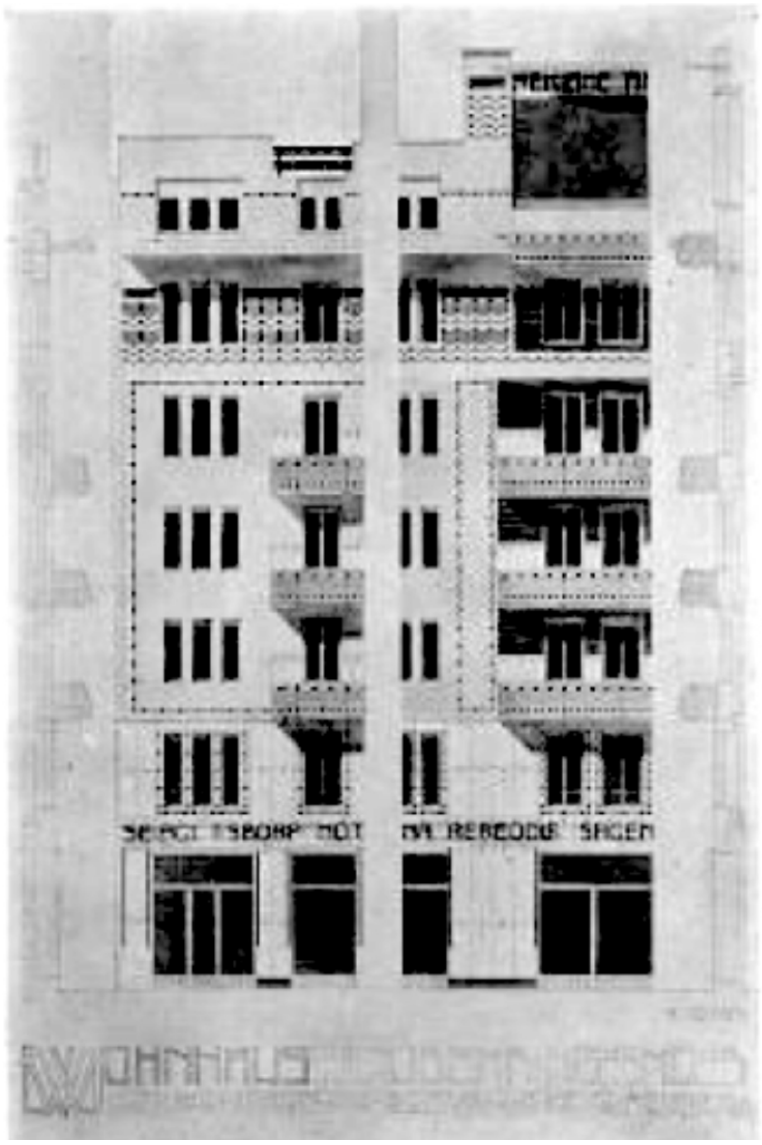

Figura 2 | Projeto de edifício habitacional para a Wagnerschule. Projeto de Anton Floderer.

Fonte: WAGNER, Otto. Wagnerschule : Projekte, Studien und Skizzen aus der Spezialschule für Architektur des Oberbaurat Otto Wagner, Professor an der K. K. Akademie der Bildenden Künste in Wien. Leipzig : Baumgärtner, 1905-1910, s.p. 
A contrassenso, a posterior prática profissional de Floderer em seu período em Berlim se versou frequentemente sobre o classicismo, às vezes mais rigoroso, às vezes mais abstrato. Mais do que uma predileção pessoal, Floderer parecia estar em sintonia com as expectativas do mecenato estatal, especialmente nos concursos arquitetônicos, tendência que parece ter sido seguida também no Brasil.

Exemplo de tal dicção monumental e historicista de Floderer se expressa no concurso para o Parlamento e para o Palácio da Justiça de Sarajevo de 1910 (TELESKO, 2017). Segundo projeto de Floderer, a fachada do Palácio de Justiça de Sarajevo apresentaria uma dicção neoclássica, tendo o entablamento gravado com os dizeres "direitos iguais para todos" e o frontão extensamente ocupado por uma dedicatória ao Kaiser. Para o Parlamento, as demandas do projeto eram mais complexas: previam uma ponte cruzando o rio Miljacka, conectando o edifício à prefeitura. A ponte, tão larga que se conformaria como uma grande praça cívica, receberia uma estátua equestre do Kaiser, que ocuparia o antigo centro otomano da cidade, um claro símbolo do domínio Habsburgo sobre a Bósnia e Herzegovina ( Figura 3). 

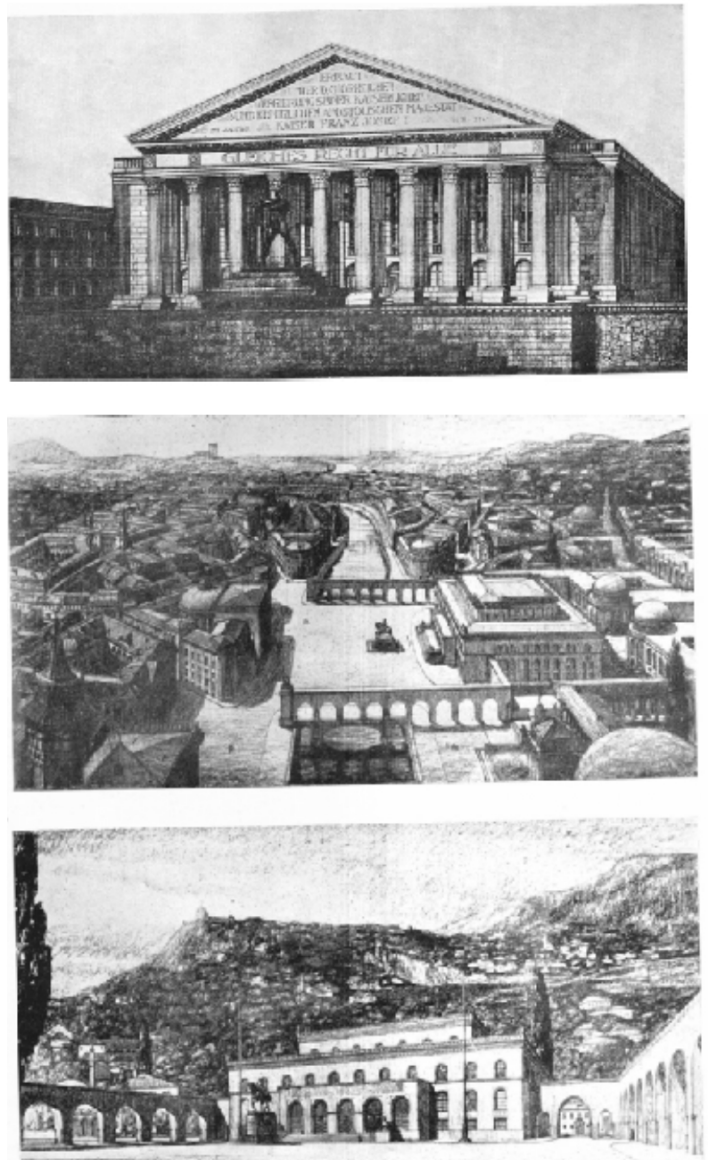

Figura 3 | Concurso para o Palácio de Justiça e o Parlamento em Sarajevo. Projeto de Anton Floderer.

Fonte: Revista “Der Architekt,"Viena: 1913, p. 105-110. 
Apesar de ocupado desde 1878, o território da Bósnia e Herzegovina foi anexado ao Império Austro-Húngaro apenas em 1908, passando a partir de então por um movimento de crescente autonomização. O concurso do qual Floderer participou celebrava justamente a proclamação da constituição e a formação do parlamento. Apesar de ficar em segundo lugar no certame, o projeto para Sarajevo não seria executado de toda forma, por conta da eclosão da Primeira Guerra Mundial (DER ARCHITEKT, 1913).

Em Berlim, já diplomado, os mais significativos projetos de Floderer ocorreram nos três anos em que passou no escritório de Bruno Schmitz, no qual colaborou com projetos bastante significativos, como o Museu de Mannheim e a monumental Ópera de Berlim². Antes da Primeira Guerra, já em seu próprio escritório, Floderer projetou residências unifamiliares no bairro berlinense de Wilmersdorf, além de lecionar em escolas técnicas da cidade. Muitos de seus projetos do período visavam concursos arquitetônicos por toda a Alemanha, estes publicados, sem serem, entretanto, contemplados. Dentre eles, destacam-se os projetos para a Prefeitura de Rottenmann, o Dienstgebäude der Reichversicherungsanstalt für Angestellte em Berlim, a Rathaus der Residenzstadt em Potsdam, o Deutsche Kasino em Praga e Kaiserplatz em

2. Além de Schmitz, Floderer se associou em Berlim a Robert Leibnitz (1911-12) e Oskar Kaufmann (1913-14). 
Königsberg, todos esses publicados em 1914 (VON FELDEGG，1910-1921; BERGER，1910-1921). O projeto do Kaiseplatz, em especial, apresenta um repertório classicista muito próximo de referências correntes em Viena, como a Coluna de Trajano revisitada por Fischer von Erlach na Karlskirche, além de um vasto repertório clássico romano, de estátuas equestres sobre arcos triunfais (Figura 4). Os projetos desse período tinham em geral uma dicção claramente classicista, mas prescindiam muitas vezes das canônicas ordens arquitetônicas, em consonância com as correntes arquitetônicas da Wagnerschule. De Wagner, Floderer herdou sobretudo a monumentalidade, que se manifesta não apenas na escala e na volumetria dos edifícios, mas também nas grandes explanadas, arcos-triunfais, estátuas equestres, escadarias, vedute e fachadas simétricas, como patente nos projetos para concursos. No caso da Igreja do Jubileu do Kaiser, predomina claramente a verticalidade dos frisos, e da Galeria de Pintura de Reichenberg, a volumetria prismática, simétrica, do edifício e de sua cúpula, em detrimento do ornamento historicista (Figura 5). Para além de tal dicção clássica prismática, devemos destacar o exemplo da mansão em Lankwitz, que foge à monumentalidade dos demais projetos e precede a linguagem arquitetônica das mansões projetadas por Floderer no Brasil (Figura 6) ${ }^{3}$.

3. A Villa Broe e a Villa Figueira (1956) são exemplos da arquitetura residencial de Floderer no Brasil, mas seus projetos ainda não foram localizados. 

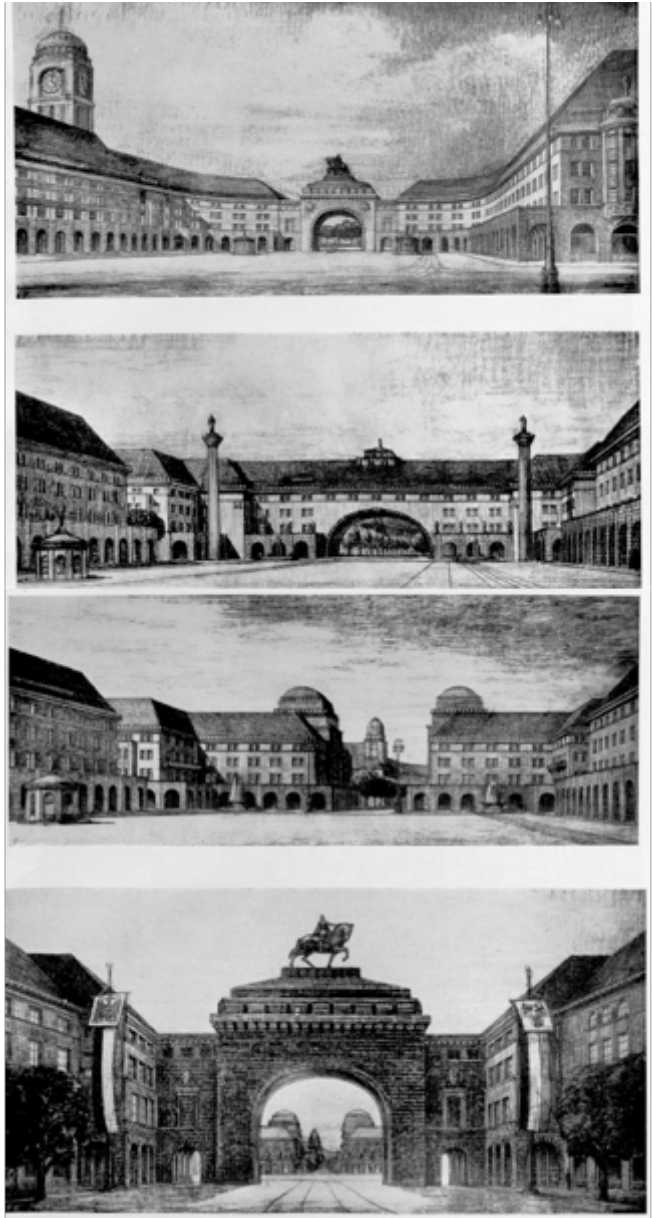

Figura 4 | Concurso para Kaiserplatz. Projeto de Anton Floderer. Fonte: : DER ARCHITEKT. Viena: 1914,p.97-97. 

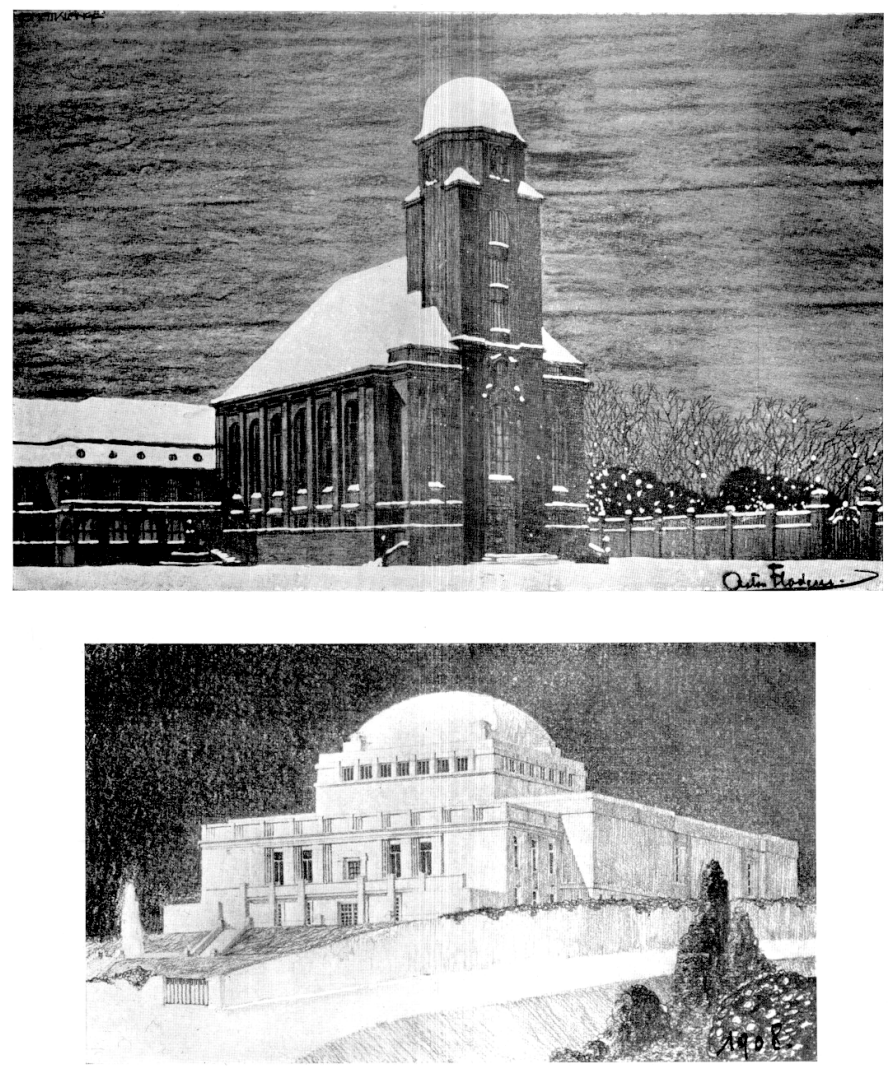

Oben: Konkurrenzprojekt für die evangel. Kaiser Franz Josef Jubiläumshirche in Wien Unten: Konkurrenzprojekt für die Gemäldegalerie in Reicbenberg Frctiteht Anton Floterze, Whlmersdonf

Figura 5 | Concurso para Igreja Evangélica do Jubileu do Kaiser Franz Josef em Viena e para Galeria de pinturas de Reichenberg. Projetos de Anton Floderer.

Fonte: Revista “Der Architekt," Viena: 1913, p. 105-110. 

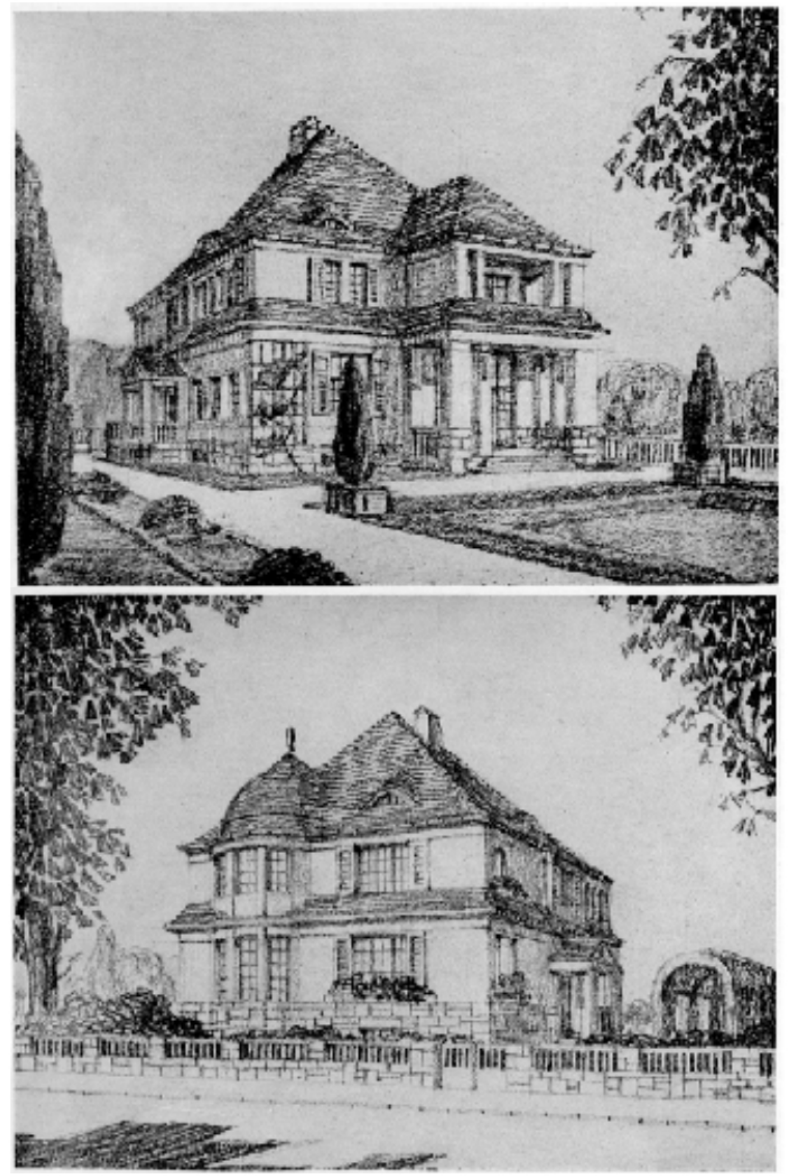

Figura 6 | Villa em Lankwitz. Projeto de Anton Floderer. Fonte: DER ARCHITEKT. Viena: 1914, p. 103-104. 
Após servir como capitão do exército Austro-Húngaro durante a Primeira Guerra Mundial, Floderer buscou brevemente se estabelecer em Viena, mas por conta da crise econômica sem precedentes do período entreguerras, viu na emigração para os Estados Unidos em 1923 uma alternativa para sua vida profissional. A emigração de Floderer para os Estados Unidos, entretanto, foi seguida de uma reemigração para o Brasil, algo ainda não totalmente esclarecido. Chegando ao Brasil nesse mesmo ano, as primeiras obras de Floderer no país sucederam ao impacto da Semana de Arte Moderna de 1922 e antecederam as casas modernistas de Warchavchik em São Paulo, ainda que a filiação de Floderer ao modernismo tivesse sido então abandonada em favor do historicismo.

A inserção de Floderer no campo arquitetônico brasileiro foi bem-sucedida desde o início graças a sua associação ao escocês Robert Russell Prentice, arquiteto que gozava de grande prestígio entre a elite da capital federal. De seu período associado a Prentice, destacam-se projetos alinhados ao neoclassicismo, como a Mapoteca do Itamaraty (1928-1930), finalista de um concurso promovido pelo Instituto de Arquitetos do Brasil; a Estação Leopoldina no Rio de Janeiro (1924-1928), e o British Bank of South America (1928) em São Paulo, um exemplo de sua aproximação paulatina com as formas sintéticas do chamado Art Decó (RIBA..., 2020). 
O Edifício Itaoca (1927) - um importante marco do desenvolvimento da dicção decorativa Marajoara no Brasil - é outro projeto de Floderer e Prentice que condiz com a experiência do austríaco com o decorativismo que desenvolvera como estudante da Wagnerschule (Figura 7). Anos mais tarde, a dicção Marajoara se faria presente em outro projeto de Floderer, dessa vez associado a Buddeus: a decoração interior do Instituto do Cacau, em Salvador ( Figura 8).

Alexander Siegfried Buddeus então professor da Escola Nacional de Belas Artes recém-contratado por Lúcio Costa em 1931 uniu-se ao escritório Floderer \& Prentice e à construtora dinamarquesa Christiani \& Nielsen, valendose do mecenato estatal na capital baiana. Do período na Bahia, destacam-se os projetos da reforma do Elevador Lacerda (1928), do Instituto do Cacau (1932-1934) de dicção Expressionista no exterior e Marajoara no interior do Palace Hotel e, cogitamos ainda, uma possível colaboração de Floderer no projeto do Instituto Normal da Bahia, por ser um projeto da Christiani \& Nielsen, sendo o escritório Floderer \& Buddeus muito ativo em Salvador nesse período. Da associação de Buddeus a Floderer, o mais antigo projeto encontrado foi a Usina do Gasômetro em Porto Alegre (1927). Enquanto eram executadas as obras de Salvador, outros projetos do escritório se desenvolviam no Rio de Janeiro, como a Igreja Santo Antônio em Teresópolis (1933), projeto influenciado pela arquite- 
tura de Clemens Holzmeister (WEIMER, 2004). Também notável é a participação do escritório Floderer \& Buddeus no Salão de Arquitetura Tropical (Rio de Janeiro, 1933), no qual apresentaram o projeto do Rio Cricket Athletic Club (1934 - Figura 9) (ASSOCIAÇÃO..., 1932). Esse evento foi bastante importante para o desenvolvimento do modernismo do Brasil e, principalmente, do desenvolvimento da sociabilidade entre arquitetos modernos, estrangeiros e nacionais. Entre os imigrados, estavam Gregori Warchavchik então associado a Lúcio Costa, Anton Floderer, Alexander Buddeus e Alexander Altberg, designer do catálogo da exposição. Entre os nacionais, muitos arquitetos próximos a Lúcio Costa: Alcides Rocha Miranda, João Lourenço da Silva, Affonso Eduardo Reidy, Emilio Baumgart, Gerson Pinheiro, Marcelo Roberto, Luis Nunes, Vicente Batista e Ademar Portugal.

Conquistando sua autonomia profissional ao longo dos anos, Floderer projetou edifícios residênciais de pequeno porte em seu escritório, como o Tofic Nigri (1931), além de edifícios autofinanciados, visando a renda imobiliária. Tais obras de Floderer no Brasil demonstram como sua arquitetura estava sintonizada, não apenas com as vertentes arquitetônicas alemãs, como o Expressionismo e a Wagnerschule, mas também alinhada às demandas do governo Vargas. O governo Vargas, por oposição à "República Velha" e por afirmar posteriormente o "Estado Novo," buscava uma linguagem arquitetônica monumen- 
tal, grandiloquente, mas modernizada, muitas vezes com cor local e nativista, como a dicção Marajoara sugeria. Era fundamental, no entanto, que tal modernidade propusesse o futuro em suas formas, mas se afastasse da radicalidade a-histórica e, principalmente, da crítica política e social do modernismo europeu (AZEVEDO, 2008).

No contexto entreguerras, permeado por extremos políticos, tanto no Brasil, quanto na Europa, devemos nos questionar acerca do posicionamento político de Floderer. Se à primeira vista isso parece não dizer muito sobre sua posição no campo arquitetônico, tal perfil político é fundamental para compreendermos o mecenato estatal o qual Floderer visava, tanto na Áustria, quanto no Brasil da Era Vargas. Sobre seu engajamento político na Europa, sabemos que ainda muito jovem Floderer serviu ao exército Austro-Húngaro voluntariamente em 1904, e posteriormente lutou na Primeira Guerra Mundial, alcançando a patente de capitão. Seus projetos arquitetônicos também dialogavam com o contexto político europeu: sua participação no concurso para Sarajevo, como vimos, se enquadra no imperialismo Austro-Húngaro pós-ocupação da Bósnia e Herzegovina, que antecedeu a Primeira Guerra Mundial. 


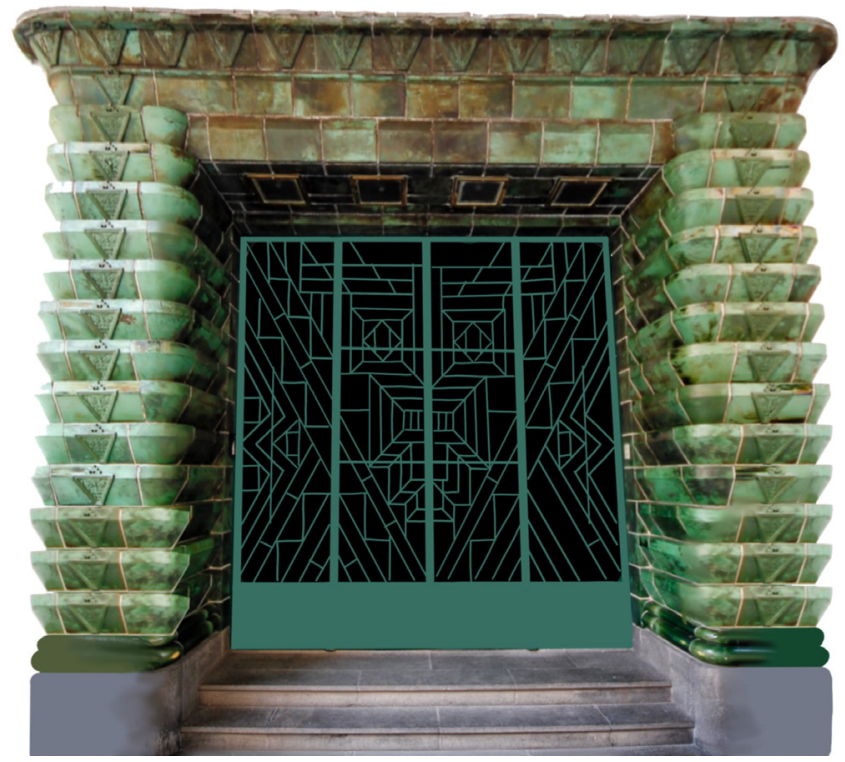

Figura 7 | Esquema compositivo da entrada do Edifício Itaoca, Rio de Janeiro. Projeto de Robert Russell Prentice e Anton Flodere.

Fonte: Arquivo Pessoal Liszt Vianna Neto. 


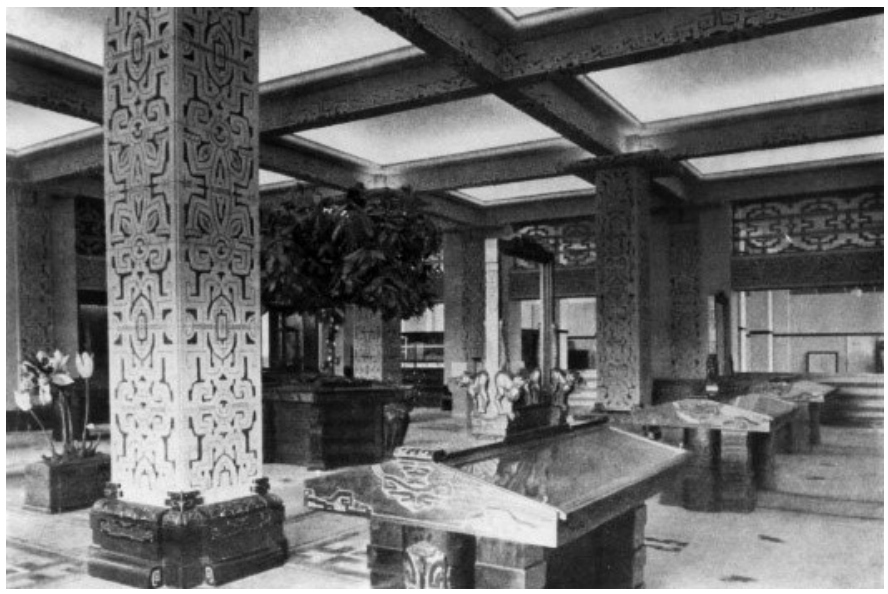

Figura 8| Relevos Art Decó Marajoara no interior do Instituto do Cacau, Salvador, Bahia. Projeto de Alexander S. Buddeus e Anton Floderer

Fonte: AZEVEDO, Paulo Ormindo de. "Alexander S. Buddeüs: a passagem do cometa pela Bahia".

Arquitextos nº81.01 São Paulo, Portal Vitruvius, jan. 2008. 

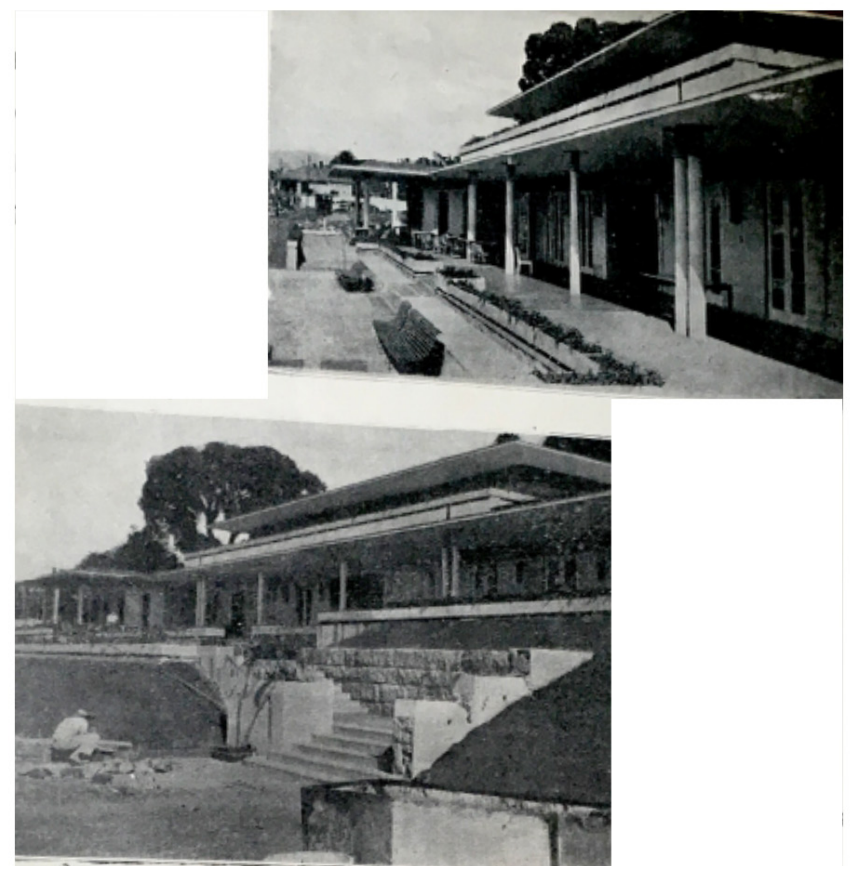

Figura 9 | Rio Cricket Athletic Club, Projeto de Anton Floderer e Alexander S. Buddeus. Fonte: CATÁLOGO da I Exposição de Arquitetura Tropical, s.p. 
Apesar de sua posição privilegiada e confortável entre a elite carioca e o mecenato estatal através da Christiani \& Nielsen, não temos referências claras acerca do alinhamento político de Floderer. Sua inserção no Jockey Club do Rio de Janeiro, como parceiro de Buddeus em torneios de tênis, e seu projeto de reforma da sede do Gesellschaft Germania, epicentro da sociabilidade da elite teuto-carioca, no entanto, o colocam em uma posição social bastante privilegiada dentre a elite da capital federal. Apesar do nome de Floderer não constar no DOPS, Delegacia de Ordem Política e Social, ou em qualquer lista de associados ao partido nazista no Brasil, o então jovem arquiteto berlinense Alexander Altberg relatou ter seus serviços rejeitados por Floderer por razões estritamente anti-semitas: "Porque o senhor não vai procurar trabalho com sua turma de judeus?" (MOREIRA, 2005). Floderer retornou à Áustria em 1939, em plena Segunda Guerra Mundial, após viver 16 anos como imigrado no Brasil, fazendo de seu retorno à Áustria algo tão intrigante quanto sua vinda para o Brasil.

A atuação de Floderer junto à construtora dinamarquesa Christiani \& Nielsen também nos oferece indícios sobre seu posicionamento político. O primeiro projeto de Floderer \& Prentice no Brasil, o British Bank of South America, foi executado pela construtora em 1924. Da mesma forma, os inúmeros projetos de Floderer junto à construtora em Salvador dão testemunho da participação da constru- 
tora na modernização da cidade durante a Era Vargas. A relação entre Floderer e a Christiani \& Nielsen foi tão estreita que $\mathrm{o}$ arquiteto foi encarregado de projetar a mansão de Harald Broe, diretor da companhia dinamarquesa no Brasil. Por conta da simpatia de Broe com a causa germânica na Segunda Guerra Mundial e das relações escusas da construtora com o regime alemão, o governo norte-americano adicionou a construtora na lista negra de empresas associadas ao nazismo em 1942, ano em que o Brasil declarou guerra aos países do Eixo (ANDERSEN, 2008).

Sabemos também que, de volta à Áustria, Floderer serviu no Departamento de Construção da Força Aérea (Luftwaffenbauamt) em Brünn, Praga e Viena. Seu retorno durante a Segunda Guerra Mundial, assim como seu engajamento na Primeira, parecem indicar que, mais do que uma simples convocação, havia em Floderer um comprometimento com a causa nacional austríaca.

Ainda que algumas questões acerca da formação e da atuação de Floderer no campo arquitetônico vienense e berlinense estejam bem delineadas, parte considerável de sua carreira no Brasil permanece como um intrigante objeto de investigação. Questões fundamentais, como os motivos que impeliram sua reemigração dos Estados Unidos em 1923, seu retorno à Europa em 1939 e sua reemigração para o Brasil no final da década de 1950, perma- 
necem sem resposta. Também não sabemos o suficiente acerca do ideário político de Floderer, ou mesmo como tal ideário pode ter influenciado sua inserção dentre a clientela imigrada, dentre o mecenato estatal da Era Vargas e dentre o campo arquitetônico carioca.

Sendo Floderer o único representante conhecido da Escola Austríaca de Otto Wagner no Brasil, assim como um singular arquiteto da dicção decorativa Marajoara e do Expressionismo Alemão, é fundamental a investigação das matrizes arquitetônicas alemãs e austríacas na formação do modernismo brasileiro através de sua obra. A arquitetura de Floderer, como a Wagnerschule, conciliou tradição e futuro para além da dicotomia modernista entre forma e função. Dada a multiplicidade de tendências na posição liminar entre o historicismo e o modernismo, a historiografia negou a muitos alunos de Wagner o título de "modernos", mesmo que estes se declarassem aderentes incondicionais ao modernismo. Ao negar-lhes tal título, tal historiografia fez com que esses arquitetos permanecessem simplesmente incompreendidos e esquecidos pelas novas gerações. Ao longo de sua convoluta trajetória, entre idas e vindas da Europa para o Brasil, Floderer se manteve próximo de valores wagnerianos, produzindo uma arquitetura diversa, múltipla e dialógica. O modernismo não seria, afinal, feito apenas por revolucionários radicais, como Adolf Loos, mas também por reformistas, como Otto Wagner e seu discípulo Anton Benjamin Floderer. 


\section{Referências}

ANDERSEN, Steen. Escaping "Safehaven": The Case of Christiani \& Nielsen's Blacklisting in 1944. EBHA Conference, 2008, s.p.

ASSOCIAÇÃO DOS COSTRUTORES CIVIS DO RIO DE JANEIRO. A Casa: Revista BiMensal de Architectura e Arte Decorativa. Sede e campo do Rio Cricket Athletic Club. Rio de Janeiro: Ricardo Wriedt, 1932. Janeiro de 1932, n.92, ano X, s.p.

AZEVEDO, Paulo Ormindo de. "Alexander S. Buddeüs: a passagem do cometa pela Bahia". Arquitextos no. 081.01. São Paulo, Portal Vitruvius, jan. 2008, s.p.

BERGER, Hans. Der Bautechniker. Viena: Perles Verlag, A. Berg. Viena: XLI, nr. 20, 1921, p. 159; Ibd., XXX, nr. 40, 1910, p. 753; Ibd., XXXII, nr.34 1912 p. 846; Ibd., XXXIII, nr.18, 1913 p. 393; Ibd., XXXIII, nr.18, 1913, s.p.

BORSI, Franco; GODOLI, Ezio. Wiener Bauten der Jahrhundertwende: $d$. Architektur d.habsburg. Metropole zwischen Historismus u. Moderne. Stuttgart: Dt. Verl. Anst., 1985, p.204.

GRAF, Otto. Die vergessene Wagnerschule. Wien: Verl. Jugend u. Volk, 1969, p. 7-12 
GRUEFF, Liliana. Disegni della Wagnerschule. Firenze: Cantini, 1989, p. 7-27

MOREIRA, Pedro. "Alexandre Altberg e a Arquitetura Nova no Rio de Janeiro". Arquitextos n 058. São Paulo, Portal Vitruvius, 2005, s.p.

POZZETTO, Marco. Die Schule Otto Wagners. Wien: Schroll, 1980, p. 9-31.

RIBA ARCHITECTURE. Verbete: "Floderer". Image Library Number: RIBA23852; RIBA23853; RIBA23854; RIBA23855; RIBA23856; RIBA23857; RIBA23858; RIBA23859; RIBA23860; RIBA23861. London, 2020. Disponível em: https://www.architecture.com/imagelibrary/ ribapix.html?keywords=floderer. Acesso em: 10 nov. 2020.

REIS, Márcio Vinícius. O Art Decó na Obra Getuliana. São Paulo. Tese de doutoramento defendida pela Faculdade de Arquitetura e Urbanismo da USP, 2014, p. 59.

TELESKO, Werner (Hg.). Die Represäntation der Habsburg-Lothringischen Dynastie in Musik, visuellen Medien und Architektur, 1618-1918. Viena: Böhlau Verlag, 2017 p.174-175.

VON FELDEGG, Ritter. Der Architekt. Viena: Anton Schroll \& Co. n. XVI, 1910, p. 33; Ibd., n. XIX, 1913, p. 24, 
p. 53; Ibd., 1914, s.p.; Ibd., 1919, s.p.; Ibd., 1920, s.p.; lbd., 1921, s.p.; lbd. 1913, p. 105-110.

VYBÍRAL, Jindich. The Wagnerschule. In: Centropa, n. 6, 2006, 1, p. 3-7.

WEIMER, Günter. Arquitetos e Construtores no Rio Grande do Sul - 1892 - 1945. UFSM, 2004.

WAGNER, Otto. Wagnerschule: Projekte, Studien und Skizzen aus der Spezialschule für Architektur des Oberbaurat Otto Wagner, Professor an der K. K. Akademie der Bildenden Künste in Wien. Leipzig: Baumgärtner, 19051910, s.p. 